\title{
Aberrant Cell Proliferation by Enhanced Mitochondrial Biogenesis via mtTFA in Arsenical Skin Cancers
}

\author{
Chih-Hung Lee, ${ }^{*}$ Shi-Bei Wu, ${ }^{\dagger}$ Chien-Hui Hong, ${ }^{\ddagger}$ \\ Wei-Ting Liao, ${ }^{*}$ Ching-Ying Wu, * \\ Gwo-Shing Chen, ${ }^{*}$ Yau-Huei Wei, ${ }^{\dagger \S}$ \\ and $\mathrm{Hsin}-\mathrm{Su} \mathrm{Yu}^{*}$

\begin{abstract}
From the Department of Dermatology,* Graduate Institute of Medicine, Center of Excellence for Environmental Medicine, Kaohsiung Medical University, Kaohsiung; the Department of Biochemistry and Molecular Biology, ${ }^{\dagger}$ National Yang-Ming University, Taipei; the Department of Dermatology, ${ }^{\ddagger}$ Kaohsiung Veterans General Hospital, Kaohsiung; and the Department of Medicine, ${ }^{\S}$ Mackay Medical College, New Taipei City, Taiwan
\end{abstract}

Arsenic-induced Bowen's disease (As-BD), a cutaneous carcinoma in situ, is thought to arise from gene mutation and uncontrolled proliferation. However, how mitochondria regulate the arsenic-induced cell proliferation remains unclear. The aim of this study was to clarify whether arsenic interfered with mitochondrial biogenesis and function, leading to aberrant cell proliferation in As-BD. Skin biopsy samples from patients with As-BD and controls were stained for cytochrome $c$ oxidase (Complex IV), measured for mitochondrial DNA (mtDNA) copy number and the expression levels of mitochondrial biogenesis-related genes, including peroxisome proliferator-activated receptor gamma coactivator$1 \alpha$ (PGC-1 $\alpha$ ), nuclear respiratory factor 1 (NRF1), and mitochondrial transcription factor $A$ (mtTFA). The results showed that expression of cytochrome $c$ oxidase, mtTFA, NRF-1, and PGC-1 $\alpha$ was increased in As-BD compared with in healthy subjects. Treatment of primary keratinocytes with arsenic at concentrations lower than $1.0 \mu \mathrm{mol} / \mathrm{L}$ induced cell proliferation, along with enhanced mitochondrial biogenesis. Furthermore, we observed that the mitochondrial oxygen consumption rate and intracellular ATP level were increased in arsenic-treated keratinocytes. Blocking of mitochondrial function by oligomycin A (Complex $\mathrm{V}$ inhibitor) or knockdown of mtTFA by RNA interference abrogated arsenic-induced cell proliferation without affecting cyclin D1 expression. We concluded that mtTFA up-regulation, augmented mitochondrial biogenesis, and enhanced mito- chondrial functions may contribute to arsenic-induced cell proliferation. Targeting mitochondrial biogenesis may help treat arsenical cancers at the stage of cell proliferation. (Am J Pathol 2011, 178:2066-2076; DOI: 10.1016/j.ajpath.2011.01.056)

Inorganic arsenic is naturally occurring and universally present in the environment. In several countries, including India (West Bengal), Bangladesh, Mongolia, Taiwan, and Chile, millions of people are exposed to arsenic through drinking arsenic-contaminated water. ${ }^{1}$ Epidemiologic studies have shown that long-term exposure to arsenic may lead to the development of several cancers, including skin, lung, liver, and bladder. ${ }^{2}$ Bowen's disease is a unique skin carcinoma in situ, and patients with long-term arsenic exposure tend to develop multiple Bowen's disease after several decades. Microscopically, Arsenic-induced Bowen's disease (As-BD) is characterized by an increase in epidermal thickness, full-blown dysplasia, and individual apoptosis without penetration of basement membranes (Figure 1A). After decades of intensive laboratory and clinical research on arsenic carcinogenesis, the mechanism by which arsenic induces carcinogenesis remains elusive. Given the numerous contaminated sites that have been identified worldwide and the millions of people at risk, there is an urgent need to understand how arsenic mediates carcinogenesis.

Abnormal cell proliferation and gene mutation signal the initial steps of carcinogenesis. ${ }^{3}$ It is known that cell proliferation demands a sufficient energy supply from mitochon-

Supported by grants from the National Science Council (NSC95-2314-B-037024, NSC96-2314-B-037-043 and NSC97-2320-B-010-013-MY3), National Health Research Institute (NHRI-EO-096-PP-11 and NHRI CN-PD-9611P), Kaohsiung Medical University (KMU-QA096005), and Kaohsiung Medical University Center of Excellence for Environmental Medicine (98.2b).

C.-H.L. and S.-B.W. contributed equally to this work.

Accepted for publication January 24, 2011

Address reprint requests to Hsin-Su Yu, M.D., Ph.D., Department of Dermatology, Kaohsiung Medical University, 100 Shih-Chuan 1st Rd., Kaohsiung 807, Taiwan; or Yau-Huei Wei, Ph.D., Department of Biochemistry and Molecular Biology, National Yang-Ming University, 155 Li-Nong Rd., Sec. 2, Pei-Tou District, Taipei 112, Taiwan. E-mail: dermyu@kmu.edu.tw or joeman@ym.edu.tw. 


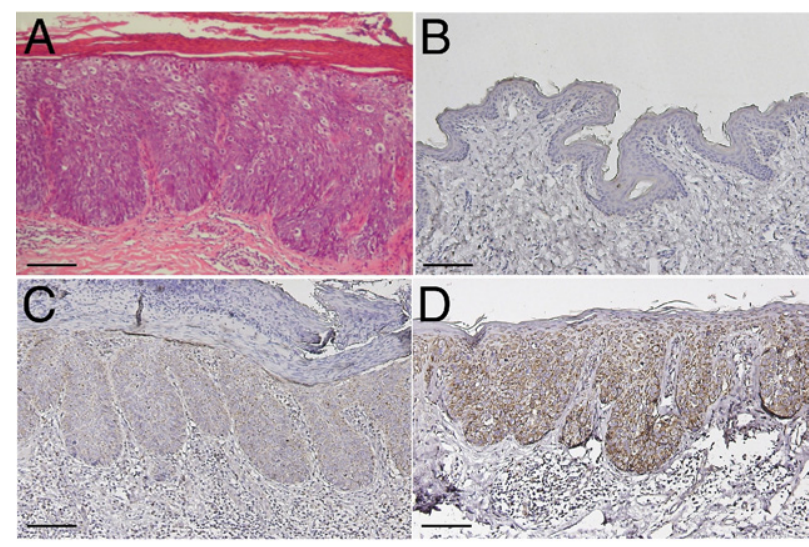

$\mathrm{E}$

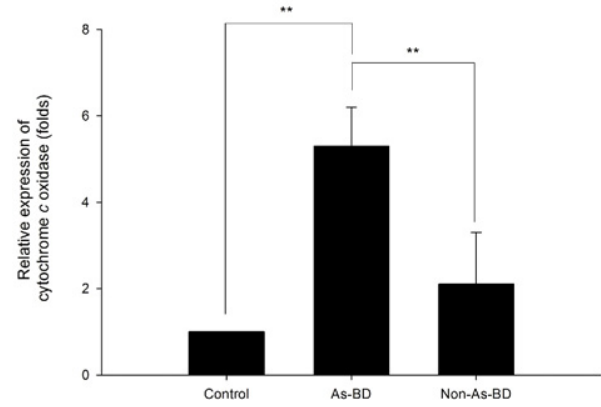

Figure 1. Cytochrome $c$ oxidase was increased in skin from patients with As-BD. A: Increases in epidermal thickness and keratinocyte proliferation in patients with As-BD (H\&E). By immunohistochemical analysis, using antibody against cytochrome $c$ oxidase, representative staining is shown for controls (B), skin with non-As-BD (C), and skin with As-BD (D). E: The quantitative bar graphic was obtained by measurement of image intensity found in $\mathbf{B}, \mathbf{C}$, and $\mathbf{D}$. Original magnification: $\times 100(\mathbf{A}) ; \times 200(\mathbf{B}-\mathbf{D})$. Scale bars $=50 \mu \mathrm{m}$. Error bars represent SD. $n=6$ in each group. ${ }^{* *} P<0.01$.

dria, the powerhouse of human cells. The mitochondria replicate to meet the energy demand of the cell. However, with an increased need for mitochondrial respiration to provide energy, cells are likely to generate more reactive oxygen species (ROS) by increased electron leakage from mitochondria. The elevated ROS can further cause damage to biological molecules, such as DNA, resulting in gene mutations. It was shown that the common 4977-bp deletion in mitochondrial DNA (mtDNA) occurred in the two most common skin cancers, basal cell carcinoma and squamous cell carcinoma. ${ }^{4}$ Arsenic acts like a double-sided sword in manipulating cell growth. On the one hand, it has been reported that arsenic induced aberrant cell proliferation, leading to human cancers ${ }^{5}$ through several survival pathways, including the extracellular signal-regulated kinase signaling pathway. On the other hand, as demonstrated in human-hamster hybrid cells, arsenic disrupted mitochondrial function, leading to an increase in intracellular ROS and mutagenic potential. ${ }^{6}$ Moreover, arsenic can induce apoptosis and serve as a promising therapeutic agent for several cancers through induction of ROS. ${ }^{7,8}$ Nitric oxide was reported to play a role in arsenic-induced gene mutations in mtDNA-depleted cells. ${ }^{9}$ However, how arsenic exerts its cell proliferative effects through regulation of mitochondrial functions remains unknown.

Functions of mitochondria are modulated by mtDNA copy number and mitochondrial biogenesis and can be reflected by mitochondrial oxygen consumption rate and intracellular level of ATP. It has been reported that mitochondrial biogenesis requires a variety of nucleus-encoded proteins, including peroxisome proliferator-activated receptor gamma coactivator-1 $\alpha$ (PGC-1 $\alpha$ ), mitochondrial DNA polymerase $\gamma$ (POLG), and mitochondrial transcription factor A (mtTFA), which contain consensus-binding sites for nuclear respiratory factors 1 and 2 (NRF-1 and NRF-2) acting on the promoters in the D-loop region of mtDNA. ${ }^{10}$ mtTFA could specify the mitochondrial transcription, translation, and replication machinery, leading to the increases in mtDNA copy number and function. ${ }^{11}$

To date, only a few articles have reported the effect of arsenic on mitochondrial function in keratinocytes, the target cells of arsenic in skin cancer. Corsini et $\mathrm{al}^{12}$ reported the role of mitochondria in arsenic-induced intracellular IL- $1 \alpha$ production. Treatment with rotenone (Complex I inhibitor) or ethidium bromide (mtDNA replication and transcription inhibitor) completely prevented arsenic-induced IL-1 $\alpha$ production in murine keratinocytes. ${ }^{12}$ Furthermore, our groups showed that He-Ne laser, a visible light laser, increased intracellular ATP content through the enhancement of cytochrome c oxidase (Complex IV) activity and mitochondrial membrane potential, as well as cell proliferation and JNK activation in human melanoma cell line A2058. ${ }^{13}$ Therefore, we investigated the role of mitochondrial biogenesis and mitochondrial function in aberrant proliferation of keratinocytes from patients with As-BD. We hypothesized that arsenic increases the expression of mitochondrial biogenesis-related genes and, thus, alters the mtDNA copy number and function of mitochondria and, ultimately, promotes aberrant cell growth.

\section{Materials and Methods}

\section{Selection of Patients}

Specimens of As-BD were obtained from patients with longterm arsenic poisoning. As-BD is different from classic Bowen's disease in its multiplicity and propensity to distribute in sun-spared skin. Furthermore, characteristic raindrop variegated hyperpigmentation and punctate palmar plantar hyperkeratosis distinguish As-BD from other forms of Bowen's disease. This study included six patients with Bowen's disease from endemic areas with a mean \pm SD age of 73.4 \pm 7.4 years in southwestern Taiwan, where artesian water was contaminated by high concentrations of arsenic. The specimens for the control group were obtained from the non-sun-exposed skin of six age-comparable patients (mean $\pm \mathrm{SD}$ age, 67.4 \pm 8.6 years) who did not live in the endemic areas and did not have a history of cancer. Another six control samples came from patients with Bowen's disease without a history of arsenic poisoning (mean $\pm \mathrm{SD}$ age, $65.3 \pm 9.4$ years). Tissues were collected and separated for the purposes of immunohistochemical analysis and extraction for RNA and DNA. The study was approved by the Institutional Review Board of Kaohsiung Medical University Hospital and was conducted according to the Declaration of Helsinki. Signed inform consent was obtained from each participant. 


\section{Chemicals and Antibodies}

Arsenic and oligomycin A were purchased from SigmaAldrich (St. Louis, MO). The monoclonal antibodies of the subunits of respiratory enzyme complexes (NDUFS3, ND4, SDHA, UQCRC2, COX II, and ATP5B) were acquired from MitoSciences (Invitrogen, Billerica, MA). The polyclonal antibodies for mtTFA and cyclin D1 were purchased from Santa Cruz Biotechnology (Santa Cruz, CA), and the $\beta$-actin antibody was from Millipore (Billerica, MA). A monoclonal antibody against cytochrome $C$ oxidase for immunohistochemical staining was purchased from Abcam Inc. (Cambridge, MA). The small hairpin RNA (shRNA) plasmids for the mtTFA gene and the luciferase control gene were obtained from the RNAi Core Facility at Academia Sinica in Taiwan.

\section{Immunohistochemical Staining of Cytochrome c Oxidase}

Paraffinized specimens were collected from the individual patches from patients with Bowen's disease. Immunohistochemical studies for cytochrome $c$ oxidase were performed on $5-\mu \mathrm{m}$ serial tissue sections mounted on $2 \% 3$-aminopropyltriethoxysilane-coated slides (Sigma-Aldrich). After deparaffinization and rehydration, slides were autoclaved in $10 \mathrm{mmol} / \mathrm{L}$ citrate buffer for 20 minutes (10 minutes in each cycle) for antigen retrieval. Endogenous peroxidase was blocked with $3 \% \mathrm{H}_{2} \mathrm{O}_{2}$ for 5 minutes. The monoclonal antibody against cytochrome $c$ oxidase (Abcam Inc.; 1:200) was incubated with the specimen overnight at $4^{\circ} \mathrm{C}$. The slides were washed with PBS and incubated with biotinylated antibody (Dako Denmark A/S, Glostrup, Denmark) for 30 minutes at room temperature. Diaminobenzidine served as the chromogenic detection reagent. The slides were counterstained with Mayer's hematoxylin for 1 minute. Dehydration and clearing of the slides were achieved in graded alcohol and xylene, respectively. Finally, the slides were mounted with Entellan (Merck, Darmstadt, Germany). Image analysis was performed using $\mathrm{NIH}$ Image $\mathrm{J}$ (http:// rsbweb.nih.gov/ij, last accessed May 28, 2010). The fluorescent intensity index (0 to 255) was calculated in five random mid-power fields above the dermoepidermal junction.

\section{Keratinocyte Cultures}

Normal human keratinocytes were obtained from adult foreskins through routine circumcision and were cultured as described previously. ${ }^{14}$ Briefly, skin specimens were washed with PBS ( $\mathrm{pH} 7.2)$, cut into small pieces, and incubated in a medium containing $0.25 \%$ trypsin (Gibco, Grand Island, NY) overnight at $4^{\circ} \mathrm{C}$. The epidermal sheet was lifted from the dermis using a fine forceps. The epidermal cells were pelleted by centrifugation $(500 \times g, 10$ minutes) and then were dispersed into individual cells by repeated aspiration with a pipette. The keratinocytes were gently resuspended in approximately $5 \mathrm{~mL}$ of keratinocyte-serum-free medium (Gibco), which contained $25 \mu \mathrm{g} / \mathrm{mL}$ bovine pituitary extract and $5 \mathrm{ng} / \mathrm{mL}$ recombinant human epidermal growth factor. The medium was changed every 2 days. Keratinocytes at the third passage were then grown in a keratinocyte-serum-free medium without bovine pituitary extract and recombinant human epidermal growth factor for 24 hours before experimentation.

\section{Protein Extraction and Western Blotting}

Proteins were extracted from cultured keratinocytes, and Western blotting was conducted as described previously. ${ }^{15}$ Briefly, total cell lysate from cultured human keratinocytes was obtained by lysis of the cells in cold radioimmunoprecipitation assay buffer $[50 \mathrm{mmol} / \mathrm{L}$ Tris- $\mathrm{HCl}, \mathrm{pH} 7.5,5$ mmol/L EDTA, 1\% Triton X-100 (Roche Diagnostics GmbH, Mannheim, Germany), $0.5 \%$ sodium deoxycholate, $0.1 \%$ SDS, $1 \%$ Nonidet P-40 (Caledon Laboratories Ltd., Georgetown, ON, Canada), and $150 \mathrm{mmol} / \mathrm{L} \mathrm{NaCl}$ ] in the presence of protease inhibitors (Roche Diagnostics $\mathrm{GmbH}$ ). After centrifugation to remove cell debris, we collected the supernatant for SDS-polyacrylamide gel electrophoresis, which was made up of $12 \%$ or $15 \%$ acrylamide under reducing conditions (in the presence of $250 \mu \mathrm{mol} / \mathrm{L} \beta$-mercaptoethanol). Proteins were subsequently electrotransferred onto a piece of nitrocellulose membrane (Sartorius AG, Göttingen, Germany) following conventional protocols. Blots were blocked in $5 \%$ skim milk/PBS with $0.1 \%$ Tween 20 (Roche Diagnostics $\mathrm{GmbH}$ ) at $4^{\circ} \mathrm{C}$ for 1 hour followed by 1 hour of incubation with primary antibodies at room temperature. After five cycles of wash with PBS with $0.1 \%$ Tween 20, the blots were incubated with secondary antibodies (horseradish peroxidase coupled with anti-mouse or anti-rabbit IgG) at 1:5000 dilution. The enhanced chemiluminescence (Amersham Pharmacia Biotech, Piscataway, $\mathrm{NJ}$ ) detection system and BioMax film (Kodak, Rochester, NY) were used to visualize specific proteins on the blots according to the manufacturer's instructions. The visualized films were recorded using a digital imaging system (Alphalmager 2000; Alpha Innotech Corp., San Leandro, CA) and were analyzed using a densitometric analysis system (AlphaEase version 3.23; Alpha Innotech Corp.). The relative intensity of each protein band was normalized to $\beta$-actin and then was normalized to the control, which had not been treated with arsenic in the same experimental set.

\section{Cell Growth and Treatment}

Cell growth was assessed by XTT assay (Sigma-Aldrich) and a commercially available 5-bromo-2'-deoxy-uridine (BrdU) labeling kit for cell proliferation (Roche Diagnostics $\mathrm{GmbH}$ ) according to the manufacturer's instruction. For XTT assay, after treatment with arsenic at the indicated time, cells were incubated with the reagent solution for 2 hours at $37^{\circ} \mathrm{C}$. Using a microplate reader, absorbance was measured at $450 \mathrm{~nm}$. On the other hand, for BrdU incorporation assay, BrdU was added to the cells, and the cells were incubated for 4 hours. After removal of the culture medium, the cells were fixed by the fixation reagent included in the kit. The anti-BrdU-peroxidase would bind to the BrdU incorporated in newly synthesized cellular DNA. The reaction product was then quantified by measurement of the absorbance at $370 \mathrm{~nm}$ using a spectrophotometer. The results were normalized with those of control groups and are expressed as relative cell growth. 
Table 1. Primer Sequences and TaqMan Probes Used in This Study

\begin{tabular}{|c|c|c|}
\hline Gene name & Primer sequence & Probe no.* \\
\hline \multirow[t]{2}{*}{ ND1 } & Forward: 5'-ACCATTTGCAGACGCCATAA-3' & \\
\hline & Reverse: 5'-TGAAATTGTTTGGGCTACGG-3' & \\
\hline \multirow[t]{2}{*}{$18 S$} & Forward: 5'-TAGAGGGACAAGTGGCGTTC-3' & \\
\hline & Reverse: $5^{\prime}$-CGCTGAGCCAGTCAGTGT-3' & \\
\hline \multirow[t]{2}{*}{$\beta$-Actin } & Forward: 5'-ATTGGCAATGAGCGGTTC-3' & 11 \\
\hline & Reverse: 5'-GGATGCCACAGGACTCCAT-3' & \\
\hline \multirow[t]{2}{*}{$P G C-1 \alpha$} & Forward: 5'-TGAGAGGGCCAAGCAAAG-3' & 66 \\
\hline & Reverse: 5'-ATAAATCACACGGCGTCTT-3' & \\
\hline \multirow[t]{2}{*}{$N R F-1$} & Forward: 5'-TGGAGTCCAAGATGCTAATGG-3' & 37 \\
\hline & Reverse: 5'-GTCTGATATCCTGGTGGTCACA-3' & \\
\hline \multirow[t]{2}{*}{ mtTFA } & Forward: 5'-CAACTACCCATATTTAAAGCTCAGAA-3' & 61 \\
\hline & Reverse: 5'-TTCTGAGCTTTAAATATGGGTAGTTG-3' & \\
\hline \multirow[t]{2}{*}{$P O L G$} & Forward: 5'-CGTCTGACATACCACGTACCC-3' & 34 \\
\hline & Reverse: 5'-CACACGGCTGGTCATAAACTC-3' & \\
\hline
\end{tabular}

*Probe numbers were referred to the Human Universal Probe Set designed for LightCycler TaqMan Master kit. For SYBR Green, no probes were used in quantitative PCR.

\section{Determination of the Expression Levels of Mitochondrial Biogenesis-Related Genes}

RNA samples from primary tissues and keratinocytes were assessed as previously described, ${ }^{14}$ and those with ratios between absorbance at 260 and $280 \mathrm{~nm}$ exceeding 1.7 were stored at $-70^{\circ} \mathrm{C}$ for further analysis. An aliquot of $5 \mu \mathrm{g}$ of RNA was used to generate cDNA with the Ready-To-Go quantitative RT-PCR kit (Amersham Biosciences, Uppsala, Sweden). The expression levels of mitochondrial biogenesis-related genes were analyzed using the LightCycler TaqMan Master Kit (Roche Diagnostics $\mathrm{GmbH}$ ) according to the manufacturer's instructions. The primer pairs and specific probe numbers are listed in Table 1, and the relative expression levels of target genes were normalized by the expression level of the $\beta$-actin gene.

\section{Determination of Mitochondrial DNA Copy Number}

The copy number of mtDNA was measured by a real-time PCR technique using the LightCycler FastStart DNA Master SYBR Green I (Roche Diagnostics $\mathrm{GmbH}$ ) according to a method described previously, ${ }^{16}$ and the primer pairs used are listed in Table 1. Briefly, an aliquot of $50 \mathrm{ng}$ of DNA was amplified in the reaction capillary containing LightCycler SYBR Green mixed reagent and each primer pair (20 $\mu \mathrm{mol} /$ $\mathrm{L})$. The real-time PCR condition was set as follows: hot start at $95^{\circ} \mathrm{C}$ for 10 minutes, followed by 45 cycles of $95^{\circ} \mathrm{C}$ for 20 seconds, $62^{\circ} \mathrm{C}$ for 20 seconds, and $72^{\circ} \mathrm{C}$ for 20 seconds. The fluorescence intensity of the PCR product was then measured at the end of the extension phase at $79^{\circ} \mathrm{C}$. The relative copy number of mtDNA was measured by normalization of the crossing points in quantitative PCR curves between the mitochondrial ND1 gene and the nuclear 18S rRNA gene, and the ratio was normalized to the control, which had not been treated with arsenic.

\section{Measurement of Intracellular ATP Content}

Intracellular ATP content was measured using the Bioluminescent Somatic Cell Assay Kit (Sigma-Aldrich) according to the manufacturer's instruction. ${ }^{17}$ Briefly, an aliquot of a 50- $\mu \mathrm{L}$ cell suspension was mixed with $150 \mu \mathrm{L}$ of Somatic Cell Releasing Reagent to release the intracellular ATP molecules, and then half of the mixture $(100 \mu \mathrm{L})$ was transferred into a black OptiPlate-96F 96-well plate (Packard Bioscience, Groningen, The Netherlands) containing $100 \mu \mathrm{L}$ of ATP Assay Mix, and the luminescence intensity was measured using the Victor2 142 counter machine (PerkinElmer Life Sciences Inc., Boston, MA). The ATP standards with a range of 0 to $300 \mathrm{pmol}$ were used, and each ATP value was normalized with the cell numbers.

\section{Mitochondrial Oxygen Consumption}

The oxygen consumption rate of the cells was measured using the 782 Oxygen Meter (Strathkelvin Instruments, North Lanarkshire, Scotland) with a water circulation system to maintain the reaction condition at $37^{\circ} \mathrm{C}$ according to a method described previously. ${ }^{18}$ Approximately $10^{6}$ cells were suspended in $330 \mu \mathrm{L}$ of assay buffer $(125 \mathrm{mmol} / \mathrm{L}$ sucrose, $65 \mathrm{mmol} / \mathrm{L} \mathrm{KCl}, 2 \mathrm{mmol} / \mathrm{L} \mathrm{MgCl}$, and $20 \mathrm{mmol} / \mathrm{L}$ phosphate buffer; $\mathrm{pH}$ 7.2) and then were transferred into the incubation chamber. After recording the rate of oxygen consumption of the cells for 5 minutes, $2 \mu \mathrm{L}$ of $250 \mathrm{mmol} / \mathrm{L}$ $\mathrm{KCN}$ was added to the chamber to inhibit mitochondrial respiration to record nonmitochondrial oxygen consumption for another 3 minutes. The rate of oxygen consumption was calculated using the SI 782 Oxygen System software version 3.0 (Warner Instruments LLC, Hamden, CT) and was normalized to the cell number.

\section{Gene Silencing by Transfection of an shRNA Plasmid}

Human mtTFA gene and luciferase gene were constructed using the shRNA expression plasmid pLKO, and the target sequences were $5^{\prime}$-CGTGAGTATATTGATCCAGAA-3' and 5'-CAAATCACAGAATCGTCGTAT-3', respectively. The keratinocytes were plated at a density of $2.0 \times 10^{5}$ cells in 60-mm culture dishes. After culture for 24 hours, transient transfection was performed with shRNA plasmid DNA and lipofectamine 2000 reagent (Invitrogen) according to the 
manufacturer's protocol. Transfected keratinocytes were then treated with arsenic to study the role of mtTFA in cell proliferation.

\section{Statistical Analysis}

Statistical analysis was performed using Microsoft Excel 2007 (Microsoft Corp., Redmond, WA), and the data are presented as mean $\pm S D$ of the results obtained from three independent experiments. The significance level of the difference between the control and experimental groups was determined by $t$-test. A difference was considered statistically significant at $P<0.05$ and $P<0.01$.

\section{Results}

\section{Enhanced Expression of Cytochrome c Oxidase in Epidermis of Lesions from Patients with As-BD}

To investigate the bioenergetic function of mitochondria in skin from patients with As-BD, we first stained cytochrome $c$ oxidase (Complex IV), the terminal enzyme of the respiratory chain of mitochondria, using immunohistochemical methods. Cytochrome $c$ oxidase was located in the suprabasal layer in the epidermis of normal skin. Compared with control skin (Figure 1B) and skin from patients with non-As-BD (Figure 1C), skin with As-BD (six of six; Figure 1D) had expression of cytochrome $C$ oxidase that was stronger and more diffusely and randomly distributed in the epidermis. The expression levels of cytochrome $c$ oxidase were quantified and are shown in Figure 1E.

\section{Increased Mitochondrial Biogenesis and lts Regulatory Molecules in As-BD}

To investigate whether the number of mitochondria was increased in skin tissue of patients with As-BD, we determined the mtDNA copy number by real-time quantitative PCR. In skin from patients with non-As-BD, there was a 1.9-fold increase in mtDNA copy number compared with that in normal skin. However, there was a significant 4.1-fold increase in mtDNA copy number in skin from patients with As-BD (Figure 2A). Although $m t D N A$ copy numbers were increased in lesions with As-BD and in lesions with non-As-BD, they were statistically significantly increased in As-BD lesions compared with in normal skin or non-As-BD lesions. Thus, we further measured and compared the expression of mitochondrial biogenesisrelated genes, including PGC- $1 \alpha$, NRF-1, mtTFA, and $P O L G$, in skin lesions from patients with As-BD and nonAs-BD. The results show that all mitochondrial biogenesisrelated genes except POLG were up-regulated in the skin of patients with As-BD compared with non-As-BD. Among them, the expression levels of PGC- $1 \alpha$ and mtTFA in the skin of patients with As-BD were significantly increased (Figure 2B; $n=6$ ). mtTFA was up-regulated most significantly of all the regulatory proteins examined.
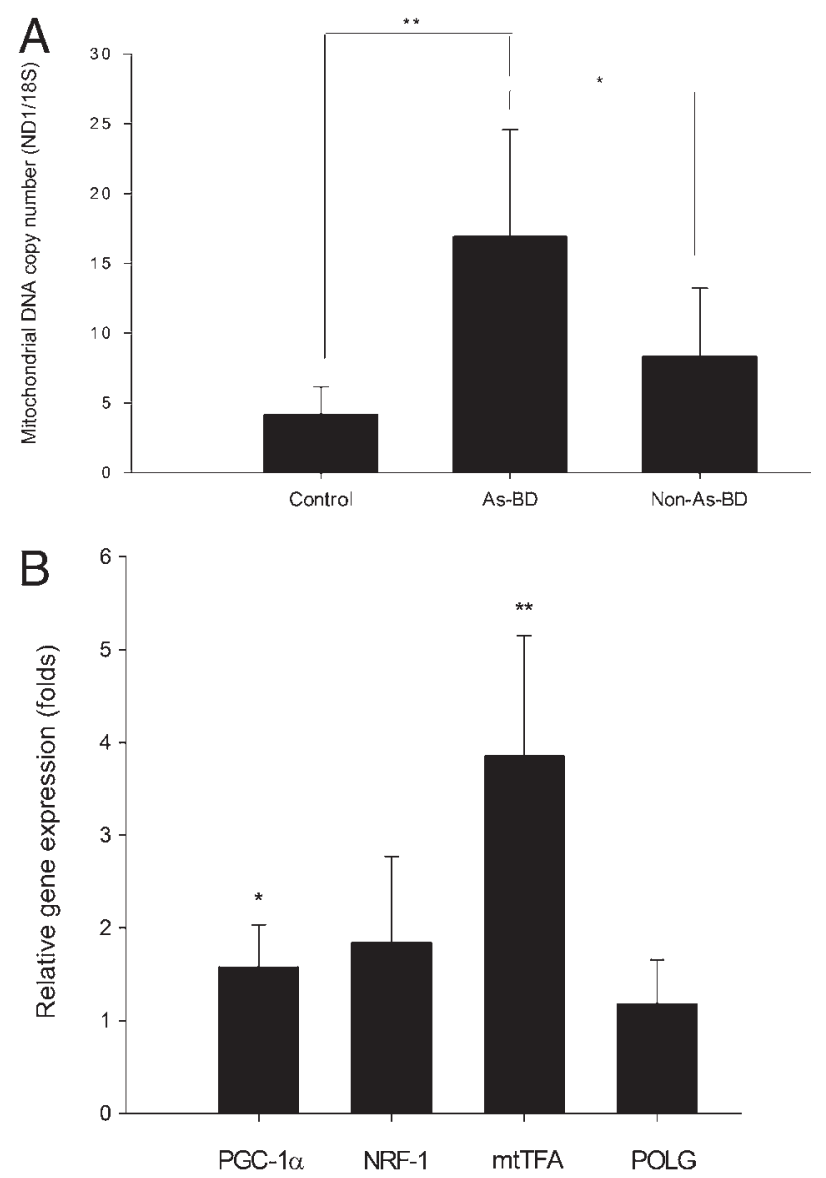

Figure 2. mtDNA copy numbers and expression of mitochondrial biogenesis-related genes were increased in skin from patients with As-BD. A: Using real-time quantitative PCR, mtDNA copy numbers were measured from skin tissues of As-BD compared with non-As-BD and controls. $n=$ 6 for each group. B: Four mitochondrial biogenesis molecules (PGC- $1 \alpha$, NRF-1, mtTFA, and POLG) in As-BD were assayed using a TaqMan-based real-time quantitative PCR system, and their expression levels were normalized with those in the non-As-BD $(n=6)$. Error bars represent SD. ${ }^{*} P$ $<0.05 ;{ }^{* *} P<0.01$.

\section{Low Concentrations of Arsenic Induced Keratinocyte Proliferation}

The observed increases in cytochrome $c$ oxidase, mtDNA copy number, and mitochondrial biogenesisrelated gene products may indicate increased cell proliferation in the skin of patients with As-BD. Thus, we asked whether arsenic promoted growth of primary keratinocytes, the target cells in As-BD. A cell viability assay revealed that arsenic at 0.1 and $1.0 \mu \mathrm{mol} / \mathrm{L}$ promoted the growth of keratinocytes at 48 and 72 hours up to $140 \%$ (Figure $3 \mathrm{~A}$ ). In contrast, arsenic at $5.0 \mu \mathrm{mol} / \mathrm{L}$ resulted in a sharp decline in cell viability. A BrdU incorporation test further confirmed the increase in cell proliferation with 0.1 and $1.0 \mu \mathrm{mol} / \mathrm{L}$ arsenic at 48 and 72 hours (Figure 3B). The representative BrdU incorporation images obtained by inverse microscopy of primary keratinocytes treated with $1.0 \mu \mathrm{mol} / \mathrm{L}$ arsenic are shown in Figure 3C. Likewise, arsenic at 5.0 $\mu \mathrm{mol} / \mathrm{L}$ decreased BrdU incorporation. 
A

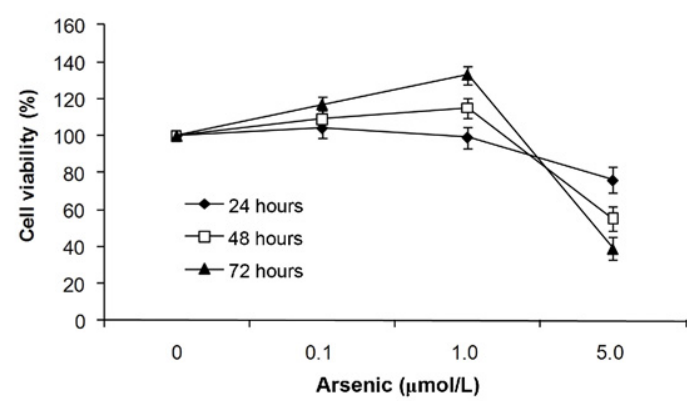

B

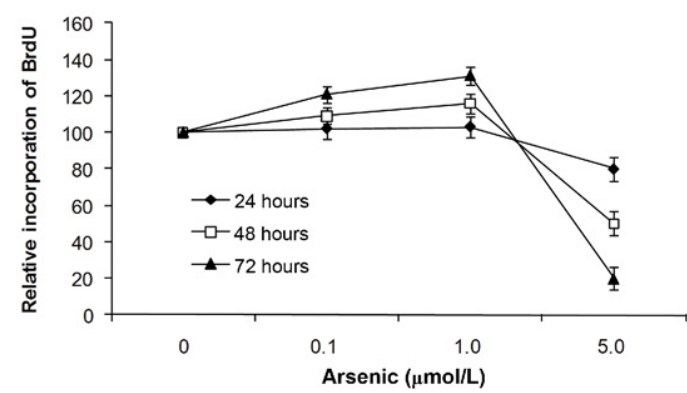

C

$1.0 \mu \mathrm{mol} / \mathrm{L}$ arsenic treatment

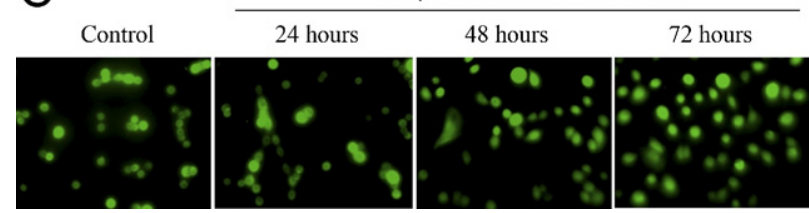

Figure 3. Induction of keratinocyte proliferation by low concentrations of arsenic. A: Arsenic at the indicated concentrations was added to cultured keratinocytes for 24,48 , and 72 hours. XTT assay was then used to estimate cell viability. B: BrdU incorporation was measured in a similar experimental protocol. C: Representative BrdU incorporation images of keratinocytes treated with arsenic at $1.0 \mu \mathrm{mol} / \mathrm{L}$ for 24,48 , and 72 hours $(n=3)$. Error bars represent SD.

\section{Increased Mitochondrial Biogenesis and mtTFA Expression in Arsenic-Treated Keratinocytes}

We then asked whether the increases in mtDNA copy number and mitochondrial biogenesis observed in As-BD could be reproduced in vitro in arsenic-treated keratinocytes. Primary keratinocytes were incubated with arsenic for 12 and 48 hours to investigate mitochondrial biogenesis-related gene expression and mtDNA copy numbers, respectively. The results show that arsenic at 0.1 and 1.0 $\mu \mathrm{mol} / \mathrm{L}$ increased the expression levels of mtTFA, PGC$1 \alpha$, and NRF-1 but not of POLG (Figure 4A). mtDNA copy numbers were significantly increased in a dose-dependent manner by $20 \%$ and $60 \%$ after 0.1 and $1.0 \mu \mathrm{mol} / \mathrm{L}$ arsenic, respectively, for 48 hours (Figure 4B). In addition, we confirmed the up-regulation of PGC- $1 \alpha$ and mtTFA at protein level after low-dose arsenic treatment for 48 hours (Figure 4C). Indeed, we noted the increase in mtTFA protein expression by 0.1 and $1.0 \mu \mathrm{mol} / \mathrm{L}$ arsenic treatment for 48 hours (Figure 4D). Therefore, confirmative kinetic studies for mtDNA copy numbers and mtTFA protein expression were performed in keratinocytes treated with arsenic at either 0.1 or $1.0 \mu \mathrm{mol} / \mathrm{L}$ for 48 and 72 hours. The increases in mtTFA protein expression and mtDNA copy number persisted for 72 hours after 0.1 and $1.0 \mu \mathrm{mol} / \mathrm{L}$ arsenic treatment (Table 2).

\section{Increased Expression of Subunits from Respiratory Enzyme Complexes and Potentiated Mitochondrial Function in Arsenic-Treated Keratinocytes}

Another assessment of mitochondrial function was acquired by analysis of the expression of the constituent subunits of respiratory enzyme complexes of mitochondria. Using Western blot analysis, we found that the subunits of NDUFS3 and ND4 of Complex I, SDHA of Complex II, UQCRC1 of Complex III, COX II of Complex IV, and ATP5B of Complex $V$ were significantly increased in keratinocytes treated with arsenic at 0.1 and $1.0 \mu \mathrm{mol} / \mathrm{L}$ for 48 hours in a dose-dependent manner (Figure 5, A and B). Similar results were obtained in keratinocytes after arsenic treatment for 72 hours (Figure 5, C and D). The result show that $1.0 \mu \mathrm{mol} / \mathrm{L}$ arsenic increased the optimum protein expression of mitochondrial respiratory enzymes at 48 hours and that $0.1 \mu \mathrm{mol} / \mathrm{L}$ arsenic persistently increased the expression of those proteins at 48 and 72 hours, both of which corresponded to the trend of mitochondrial functions (Table 2). As expected, arsenic at $5 \mu \mathrm{mol} / \mathrm{L}$ had detrimental effects on mitochondria and
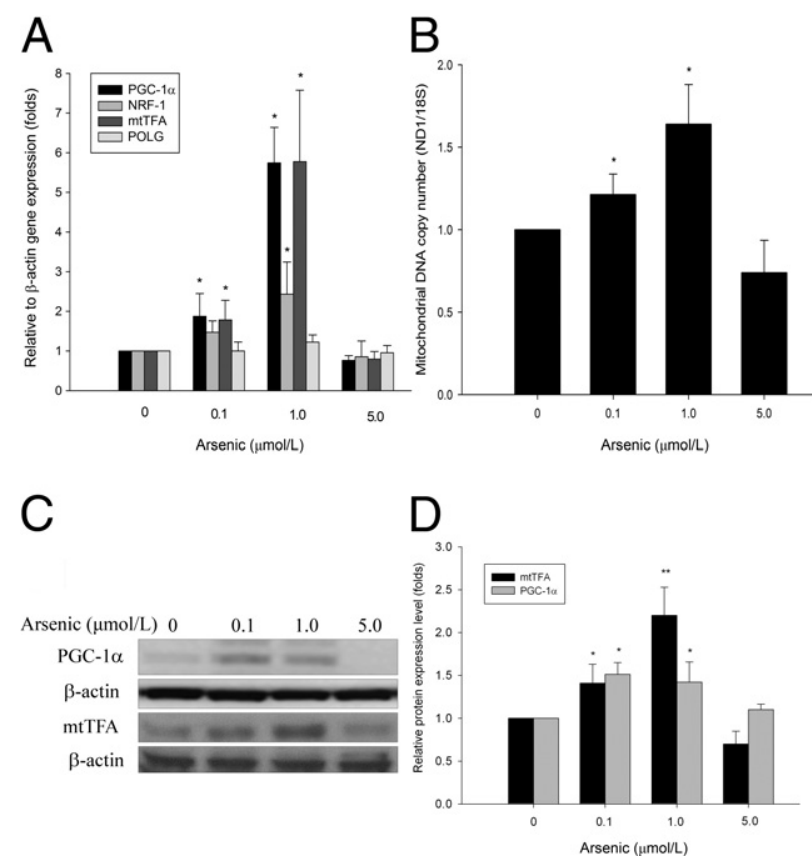

Figure 4. Increased mitochondrial biogenesis by low concentrations of arsenic treatment. A: Mitochondrial biogenesis-related genes (PGC- $1 \alpha$, NRF-1, mtTFA, and POLG) were measured after treatment with low concentrations of arsenic for 12 hours. B: MtDNA copy numbers were measured and standardized to ribosomal $18 \mathrm{~S}$ expression after treatment with arsenic at 0.1 , 1.0 , and $5.0 \mu \mathrm{mol} / \mathrm{L}$ for 48 hours. C: Protein expressions of mtTFA and PGC- $1 \alpha$ were measured using Western blot analysis after 0.1 and $1.0 \mu \mathrm{mol} / \mathrm{L}$ arsenic treatment for 48 hours. D: The quantitative bar graphic was derived from $\mathbf{C}(n=3)$. Error bars represent SD. ${ }^{*} P<0.05 ;{ }^{* *} P<0.01$ 
Table 2. Arsenic at Lower Concentrations Enhanced Mitochondrial Biogenesis, Mitochondrial Functions, and Intracellular ATP Production in Primary Keratinocytes

\begin{tabular}{|c|c|c|c|c|c|c|}
\hline & \multicolumn{3}{|c|}{ Arsenic treatment for 48 hours $(\mu \mathrm{mol} / \mathrm{L})$} & \multicolumn{3}{|c|}{ Arsenic treatment for 72 hours $(\mu \mathrm{mol} / \mathrm{L})$} \\
\hline & 0 & 0.1 & 1.0 & 0 & 0.1 & 1.0 \\
\hline $\begin{array}{l}\text { mtTFA protein } \\
\text { (relative folds) }\end{array}$ & 1.00 & $1.41 \pm 0.22^{*}$ & $2.24 \pm 0.37^{\dagger}$ & 1.00 & $2.18 \pm 0.54^{\dagger}$ & $2.72 \pm 0.63^{\dagger}$ \\
\hline $\begin{array}{l}\text { mtDNA copy number } \\
\text { (relative folds) }\end{array}$ & 1.00 & $1.21 \pm 0.12^{*}$ & $1.64 \pm 0.24^{*}$ & 1.00 & $1.74 \pm 0.42^{*}$ & $1.96 \pm 0.35^{\star}$ \\
\hline $\begin{array}{l}\mathrm{O}_{2} \text { consumption rate } \\
\left(\mathrm{nmol} / 10^{4} \text { cells/minute }\right)\end{array}$ & $1.87 \pm 0.13$ & $2.63 \pm 0.52^{*}$ & $3.52 \pm 0.27^{\dagger}$ & $2.01 \pm 0.33$ & $3.70 \pm 0.70^{*}$ & $3.18 \pm 0.38^{*}$ \\
\hline $\begin{array}{l}\text { Intracellular ATP content } \\
\text { (fmol per cell) }\end{array}$ & $7.33 \pm 0.51$ & $9.27 \pm 2.35^{*}$ & $14.18 \pm 1.74^{\dagger}$ & $8.34 \pm 0.22$ & $12.21 \pm 1.19^{*}$ & $11.86 \pm 1.58^{*}$ \\
\hline
\end{tabular}

Data are given as mean $\pm \mathrm{SD} . n=3$.

${ }^{\star} P<0.05$.

${ }^{\dagger} P<0.01$.

the integrity of respiratory enzyme complexes (Figure 5). More importantly, the increased expression of the subunits in respiratory enzyme complexes was consistent with the findings of increased expression of cytochrome $c$ oxidase (Complex IV) from skin biopsy samples of patients with As-BD (Figure 1).

We then observed the kinetic effects of arsenic in the function of the mitochondria. By analysis of the mitochondrial oxygen consumption rate and intracellular ATP content, we found that keratinocytes treated with 0.1 or 1.0 $\mu \mathrm{mol} / \mathrm{L}$ arsenic not only had more copies of mtDNA but also exhibited a significant increase in energy production and cell growth for 48 hours (Figure 3). The increases in mitochondrial function and intracellular ATP content also persisted for 72 hours after arsenic treatment (Table 2). The data suggest a dose-dependent increase in mitochondrial functions after 0.1 and $1.0 \mu \mathrm{mol} / \mathrm{L}$ arsenic treatment of keratinocytes for 48 hours. Chronologically, mitochondrial function was enhanced in a time-dependent manner by 0.1 $\mu \mathrm{mol} / \mathrm{L}$ arsenic at 48 and 72 hours and reached maximal at 48 hours after $1.0 \mu \mathrm{mol} / \mathrm{L}$ arsenic treatment. This "peak lag" might reflect the dynamic changes in metabolic needs (peak at 48 hours) before active proliferation (peak at 72 hours) after cells had been treated with an optimal but subtoxic dose of arsenic $(1.0 \mu \mathrm{mol} / \mathrm{L})$.

\section{Mitochondria and mtTFA in Arsenic-Induced Proliferation of Keratinocytes}

Because there was a parallel increase in cell proliferation and in mitochondrial replication and function, we asked whether mitochondrial biogenesis, or more specifically, the key regulator of mitochondrial biogenesis, mtTFA, was involved in the cell proliferation induced by
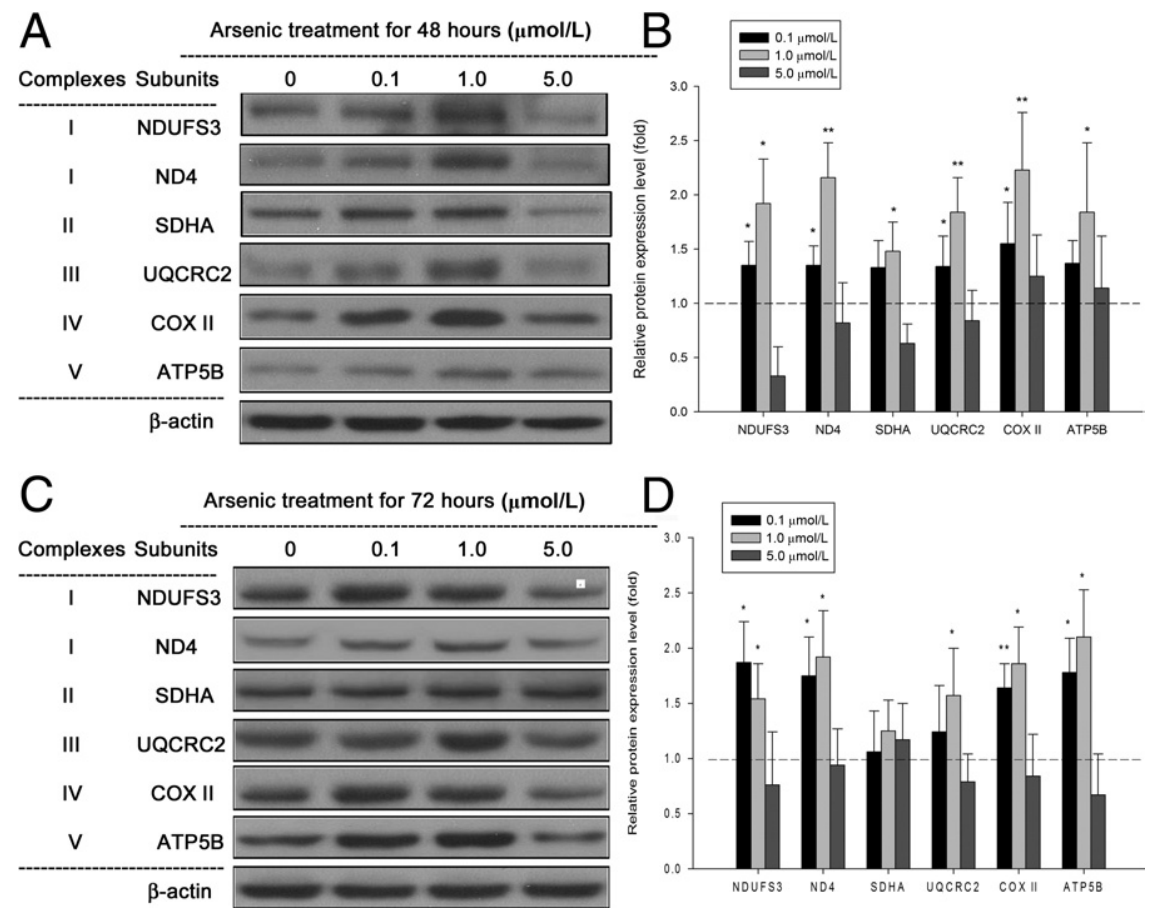

Figure 5. Up-regulation of the expression of the subunits of mitochondrial respiratory enzymes by low concentrations of arsenic. Keratinocytes were treated with arsenic at $0.1,1.0$, and $5.0 \mu \mathrm{mol} / \mathrm{L}$ for 48 hours (A and $\mathbf{B}$ ) or 72 hours $(\mathbf{C}$ and $\mathbf{D}$ ), and total cell lysate was used for Western blot analysis using corresponding antibodies $(n=3$, representative blots are shown in $\mathbf{A}$ and C). Densitometric analysis standardized by the protein expression levels of nontreated keratinocytes is shown in $\mathbf{B}$ and $\mathbf{D}(n=3)$. Error bars represent $\mathrm{SD} .{ }^{*} P<0.05 ;{ }^{* *} P<0.01$. The dashed horizontal lines in $\mathbf{B}$ and $\mathbf{D}$ represent the levels of endogenous expression of the indicated mitochondrial proteins (control without arsenic treatment) normalized to that of $\beta$-actin in keratinocytes (taken as 1.0). 
A

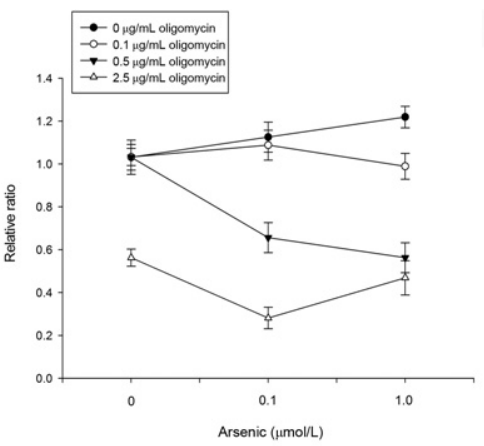

C

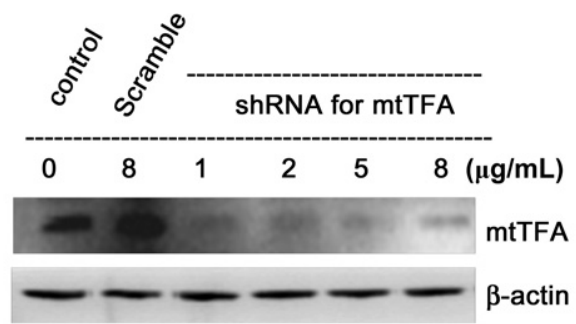

B

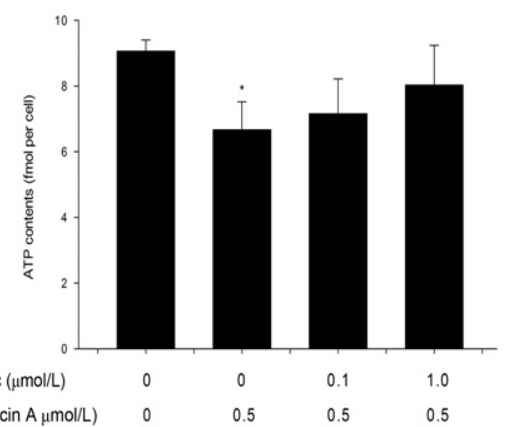

$\begin{array}{lllll}\text { Oligomycin A } \mu \mathrm{mo} / \mathrm{L}) & 0 & 0.5 & 0.5 & 0.5\end{array}$

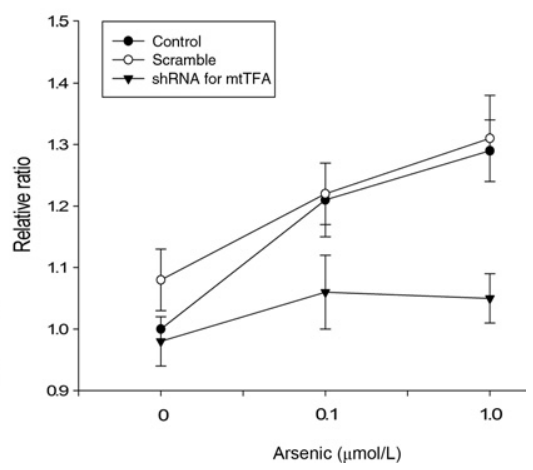

Figure 6. Significant role of mitochondria and mtTFA in the proliferation induced by low concentrations of arsenic. A: Keratinocytes were pretreated with oligomycin A at $0,0.1,0.5$, and $2.5 \mu \mathrm{g} / \mathrm{mL}$ for 1 hour, and then cells were treated with low concentrations of arsenic $(0,0.1$, and $1.0 \mu \mathrm{mol} / \mathrm{L}$ ) for 72 hours. The growth curve was normalized with the number of control cells at 72 hours. B: Keratinocytes were treated with oligomycin A at $0.5 \mu \mathrm{g} / \mathrm{mL}$ for 1 hour followed by 72 hours with arsenic at $0,0.1$, and 1.0 $\mu \mathrm{mol} / \mathrm{L}$. Intracellular ATP content was measured and is shown on the $y$ axis. ${ }^{*} P<0.05$ when comparing ATP content between the indicated group and the control group without treatment with arsenic or oligomycin. C: Keratinocytes were transiently transfected with shRNA for mtTFA or with scramble shRNA. The effect of down-regulation of mtTFA by RNA interference was revealed using Western blot analysis. D: Transfected keratinocytes were treated with the indicated concentrations of arsenic for 72 hours. Cell numbers were normalized with the number of control cells at 72 hours. Error bars represent $\mathrm{SD}$ low concentrations of arsenic. Because we had already shown that low concentrations of arsenic induced $20 \%$ to $40 \%$ of the increase in cell proliferation after 72 hours, we pretreated keratinocytes with a specific mitochondrial ATP synthase inhibitor, oligomycin A, to examine whether the proliferation could be abrogated. The results show that, while exerting no toxicity on arsenic-free keratinocytes at $0.1 \mu \mathrm{g} / \mathrm{mL}$, oligomycin $A$ significantly abrogated the proliferation induced by 1.0 $\mathrm{mol} / \mathrm{L}$ arsenic (Figure $6 \mathrm{~A}$ ). Furthermore, at $0.5 \mu \mathrm{g} / \mathrm{mL}$, oligomycin A could even reverse the growth of keratinocytes that had been treated with 0.1 and $1.0 \mu \mathrm{mol} / \mathrm{L}$ arsenic (Figure 6A). At $0.5 \mu \mathrm{g} / \mathrm{mL}$, oligomycin A could inhibit the elevated intracellular level of ATP of keratinocytes that had been induced by 0.1 and $1.0 \mu \mathrm{mol} / \mathrm{L}$ arsenic (Figure 6B). However, it might be argued that oligomycin $A$ had other nonmitochondrial effects. Therefore, to address specifically the role of mtTFA in the cell proliferation induced by arsenic, we transfected the keratinocytes with an shRNA for mtTFA. Using Western blot analysis, we showed that mtTFA was decreased in mtTFA-shRNA-transfected keratinocytes but not in scramble-shRNA-transfected keratinocytes (Figure $6 \mathrm{C}$ ). After transfection with $8 \mu \mathrm{g} / \mathrm{mL} \mathrm{mt}-$ TFA-shRNA or scramble-shRNA in keratinocytes for 24 hours, we treated transfected keratinocytes with 0.1 and $1.0 \mu \mathrm{mol} / \mathrm{L}$ of arsenic, respectively, for another 72 hours. The results showed that arsenic-induced cell proliferation was abrogated in cells transfected with mtTFA-shRNA but not in those transfected with scramble-shRNA (Figure 6D). Thus, we conclude that arsenic-induced cell proliferation of keratinocytes depends on mtTFA up-regulation and mitochondrial biogenesis.

\section{Knockdown of mtTFA Does Not Interfere with Cyclin D1 Expression after Arsenic Treatment}

It has been shown that up-regulation of cyclin D1 is involved, at least partially, in the aberrant keratinocyte proliferation induced by arsenic. ${ }^{19}$ To determine whether knockdown of mtTFA in keratinocytes would interfere with arsenicinduced cyclin D1 expression, we treated transfected keratinocytes with $1.0 \mu \mathrm{mol} / \mathrm{L}$ arsenic for 72 hours to study cyclin D1 expression. The result show that knockdown of mtTFA in keratinocytes did not interfere with cyclin D1 expression after arsenic treatment (Figure 7), indicating that cylcin D1 induced by arsenic is independent of mtTFA expression. The enhanced mitochondrial functions, in parallel to cyclin D1 expression, may play, at least in part, a significant role in the aberrant proliferation and skin carcinogenesis by arsenic.

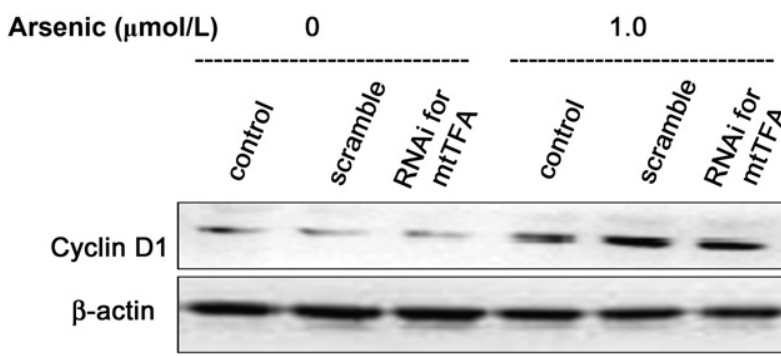

Figure 7. Knockdown of mtTFA did not interfere with cyclin D1 expression induced by arsenic. Nontransfected, scramble RNAi-transfected, and mtTFA RNAi-transfected keratinocytes were treated with $1.0 \mu \mathrm{mol} / \mathrm{L}$ arsenic for 72 hours. A representative Western blot showing cyclin D1 expression is shown $(n=3)$. 


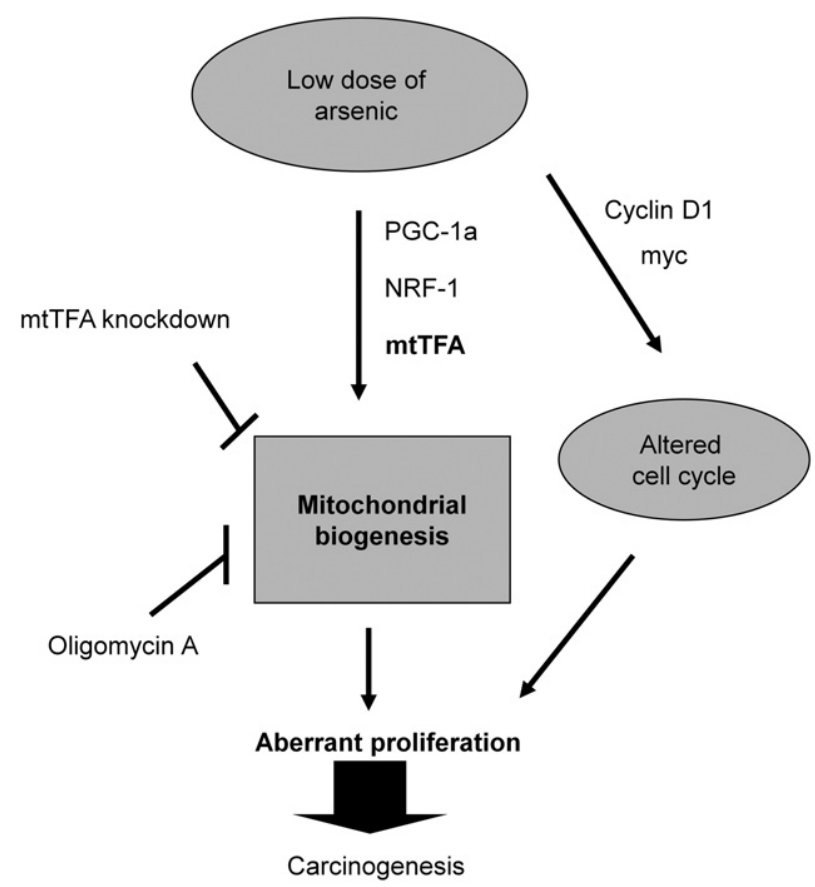

Figure 8. A proposed scheme of arsenic-induced cell proliferation via mitochondrial biogenesis in the skin of patients with As-BD. Low concentrations of arsenic $(0.1$ and $1.0 \mu \mathrm{mol} / \mathrm{L})$ induce aberrant cell proliferation through the increase of mtTFA gene expression, which results in increases in mtDNA copy numbers and the subunits of mitochondrial respiratory complexes. Enhanced mitochondrial biogenesis accompanies the increased mitochondrial oxygen consumption rate and intracellular ATP levels in cells treated with lower concentrations of arsenic. Treatment with oligomycin A or RNA interference with mtTFA to inhibit mitochondrial function inhibited arsenic-induced cell proliferation. In addition, the effects of arsenic in upregulated mtTFA and enhanced mitochondrial functions are independent of cyclin D1 expression. Therefore, mitochondrial function, particularly the regulatory factors related to mitochondrial biogenesis, might be a potential therapeutic target for the treatment of arsenic-induced cancers in the proliferation stage.

\section{Discussion}

In this study, we demonstrated that mitochondrial biogenesis and its key regulatory factor, mtTFA, were significantly up-regulated in arsenic-treated keratinocytes and skin tissues from patients with As-BD. Targeting mtTFA by RNA interference or inhibiting mitochondrial ATP synthase by oligomycin A abolished the arsenic-induced cell proliferation. Besides, not only mitochondrial biogenesis but also the bioenergetic function of mitochondria was enhanced by arsenic at lower concentrations. This study revealed for the first time, to our knowledge, that increased mitochondrial biogenesis mediated arsenic-induced aberrant proliferation of keratinocytes (Figure 8).

An abnormal increase in mitochondrial biogenesis has been linked to breast, gastric, lung, and esophageal cancers. ${ }^{20}$ Furthermore, the mtDNA content was found to increase with the histopathologic grade of cancers in the head and neck. ${ }^{21}$ Likewise, in a study of arsenic-induced skin carcinogenesis, abnormal mitochondrial biogenesis in keratinocytes might initially protect the cells against arsenic toxicity but in the long term might actually generate and accumulate more ROS to damage cellular structures and DNA, predisposing the cells to aberrant proliferation and potential carcinogenesis. ${ }^{22}$ In As-BD, oxidative DNA damage was revealed by the presence of 8-hydroxydeoxyguanosine. ${ }^{23}$ In addition, using Saccharomyces cerevisiae as a model system, several genes of mitochondrial biogenesis were reported to be involved in arsenic carcinogenesis. ${ }^{24,25}$

Previous studies on the effects of arsenic on mitochondria mostly focused on the apoptotic effects of arsenic as an anticancer drug. The disruption of mitochondrial membrane potential, the activation of proapoptotic enzymes, and the generation of ROS induced by arsenic have been previously described. ${ }^{7,26,27}$ However, it is worth noting that arsenic can exert dual effects on cell proliferation and apoptosis. ${ }^{28}$ Arsenic at concentrations up to 1.0 $\mu \mathrm{mol} / \mathrm{L}$ induced cell proliferation in keratinocytes ${ }^{19}$ (Figure 3) and peripheral blood mononuclear cells, ${ }^{29}$ whereas arsenic at concentrations higher than $5.0 \mu \mathrm{mol} / \mathrm{L}$ led to apoptosis in both cell types. It has been reported that treatment of MCF-7 breast cancer cells with low concentrations of arsenite $(0.5$ to $5 \mu \mathrm{mol} / \mathrm{L})$ induced ROS production, oxidative DNA damage, increased myc gene expression, and, ultimately, aberrant cell proliferation. ${ }^{28}$

Expressions of PGC- $1 \alpha$ and mtTFA in As-BD were found to be significantly up-regulated in this study, although mtTFA was more increased than was PGC- $1 \alpha$. Unlike mtTFA, which is a mitochondrial transcriptional factor, PGC- $1 \alpha$ is a transcription coactivator that interacts with a broad range of transcription factors, including not only NRF-1 in mitochondrial biogenesis but also many other transcriptional factors, which were involved in a variety of biological responses. ${ }^{30}$ Thus, to address the specific role of mitochondrial biogenesis in arsenic-induced cell proliferation, we decided to block mtTFA in this study. Nonetheless, we also attempted to block PGC1- $\alpha$ by RNA interference. The result showed that the efficient knockdown of PGC- $1 \alpha$ results in a dramatic decrease in keratinocyte viability with or without arsenic (data not shown). We believe that PGC1- $\alpha$ is vital to keratinocyte survival. It is difficult to address whether arsenic-induced cell proliferation was mediated by PGC- $1 \alpha$ in this context.

Among the mitochondrial biogenesis factors, mtTFA, PGC- $1 \alpha$, and NRF-1 showed parallel and significant changes in arsenic-treated keratinocytes and skin tissues from patients with As-BD as revealed in this study. The effect of arsenic on the mitochondrial genome is multifaceted through the regulation of replication and stability of mtDNA. ${ }^{31}$ It is established that not only the copy number but also the packaging of mtDNA are regulated by mtTFA. This might provide a clue that arsenic might, in fact, enhance proliferation via increased mitochondrial biogenesis through mtDNA replication-independent pathways, such as packaging of mtDNA. Although the number of the samples assayed ex vivo was limited in this study ( $n=6$ each for controls, As-BD, and non-As-BD), a consistent and reproducible trend among the tissueand cell-based assays in the assessment of effects of arsenic was observed in this study. The other limitations might include the lack of long-term treatment by even lower concentrations of arsenic (eg, for several weeks). An animal study might be a good way to further address 
the long-term effects of arsenic in vivo. Nevertheless, the findings from this study provide novel and important information about the role of mitochondrial function in arsenic-induced keratinocyte proliferation and in the pathogenesis and progression of As-BD.

It has been demonstrated that cyclin D1 expression participates in the low-dose arsenite-induced transformation in mouse epidermal JB6 Cl41 cells. ${ }^{32,33}$ Although cyclin D1 was associated with proliferation by arsenic in human primary keratinocytes, ${ }^{19}$ it remains an open question whether cyclin D1 contributed exclusively to the proliferation of keratinocytes. This study indicates that arsenic increases mitochondrial functions and proliferation through up-regulation of mtTFA, which is likely independent of cyclin D1 (Figures 7 and 8). In agreement with this, it has been reported that cyclin D1 and mitochondria might both contribute to cell proliferation in lipopolysaccharide-treated hepatocytes. ${ }^{34}$

In contrast to the requirement of mitochondria arsenicinduced cell proliferation, a well-known Warburg effect hypothesized that cancer cells develop a defect in mitochondria leading to impaired aerobic respiration followed by a compensatory increase in glycolytic metabolism. ${ }^{35}$ However, subsequent studies have shown that mitochondrial function is not inhibited in many cancer cells, especially in the initiation of cancer propagation. ${ }^{36,37}$ For example, disruption of mitochondrial function by loss of the mtTFA gene reduced K-ras-mediated tumorigenesis. ${ }^{38}$ Moreover, contradictory to the Warburg effect but similar to the present study, oxygen consumption seemed to be a rate limiting factor for tumor growth in pancreatic cancer in vitro and in vivo. ${ }^{39}$ Therefore, in these cancers, increased mitochondrial functions might provide energy for the tumors to grow. Similarly, up-regulation of mtTFA expression and mitochondrial biogenesis were found in liver tumor compared with in normal liver. ${ }^{40}$ In addition, Posey et al ${ }^{41}$ found that the level of Cox6a2, required for cytochrome $c$ oxidase activity, was increased in lung epithelial cell lines after treatment with a low concentration of arsenic $(0.75 \mu \mathrm{mol} / \mathrm{L})$.

In conclusion, we demonstrated that aberrant mitochondrial biogenesis mediated the arsenic-induced proliferation of human keratinocytes. This process was mediated via mtTFA, the main regulatory factor of mitochondrial biogenesis. The results also indicate that mitochondria play a significant role, likely independent of cyclin D1, in initiation of the growth of skin keratinocytes induced by arsenic. Therefore, mitochondrial biogenesis and its regulatory factors might be potential therapeutic targets for the treatment of arsenic-induced cancers.

\section{Acknowledgments}

We thank the core facilities at National Yang-Ming University for technical support and service. We also thank to the core supports from Center of Excellence for Environment Medicine in Kaohsiung Medical University.

\section{References}

1. Yu HS, Liao WT, Chai CY: Arsenic carcinogenesis in the skin J Biomed Sci 2006, 13:657-666

2. Tseng WP: Effects and dose-response relationships of skin cancer and blackfoot disease with arsenic. Environ Health Perspect 1977, 19:109-119

3. Hanahan D, Weinberg RA: The hallmarks of cancer. Cell 2000, 100: 57-70

4. Kamenisch Y, Wenz J, Metzler G, Bauer J, Neubauer H, Garbe C, Rocken M, Berneburg M: The mitochondrial DNA common deletion is present in most basal and squamous cell carcinoma samples isolated by laser capture microdissection but generally at reduced rather than increased levels. J Invest Dermatol 2007, 127:486-490

5. Shen J, Wanibuchi H, Salim El, Wei M, Kinoshita A, Yoshida K, Endo G, Fukushima S: Liver tumorigenicity of trimethylarsine oxide in male Fischer 344 rats: association with oxidative DNA damage and enhanced cell proliferation. Carcinogenesis 2003, 24:1827-1835

6. Partridge MA, Huang SX, Hernandez-Rosa E, Davidson MM, Hei TK: Arsenic induced mitochondrial DNA damage and altered mitochondrial oxidative function: implications for genotoxic mechanisms in mammalian cells. Cancer Res 2007, 67:5239-5247

7. Hei TK, Liu SX, Waldren C: Mutagenicity of arsenic in mammalian cells: role of reactive oxygen species. Proc Natl Acad Sci U S A 1998, 95:8103-8107

8. Liu SX, Athar M, Lippai I, Waldren C, Hei TK: Induction of oxyradicals by arsenic: implication for mechanism of genotoxicity. Proc Natl Acad Sci U S A 2001, 98:1643-1648

9. Liu SX, Davidson MM, Tang X, Walker WF, Athar M, Ivanov V, Hei TK Mitochondrial damage mediates genotoxicity of arsenic in mammalian cells. Cancer Res 2005, 65:3236-3242

10. Lee $\mathrm{HC}$, Wei $\mathrm{YH}$ : Mitochondrial biogenesis and mitochondrial DNA maintenance of mammalian cells under oxidative stress. Int J Biochem Cell Biol 2005, 37:822-834

11. Scarpulla RC: Transcriptional paradigms in mammalian mitochondrial biogenesis and function. Physiol Rev 2008, 88:611-638

12. Corsini E, Asti L, Viviani B, Marinovich M, Galli CL: Sodium arsenate induces overproduction of interleukin- $1 \alpha$ in murine keratinocytes: role of mitochondria. J Invest Dermatol 1999, 113:760-765

13. Hu WP, Wang JJ, Yu CL, Lan CC, Chen GS, Yu HS: Helium-neon laser irradiation stimulates cell proliferation through photostimulatory effects in mitochondria. J Invest Dermatol 2007, 127:2048-2057

14. Lee $\mathrm{CH}$, Yu CL, Liao WT, Kao YH, Chai CY, Chen GS, Yu HS: Effects and interactions of low doses of arsenic and UVB on keratinocyte apoptosis. Chem Res Toxicol 2004, 17:1199-1205

15. Lee CH, Chen JS, Sun YL, Liao WT, Zheng YW, Chai CZ, Chen GS, Yu HS: Defective $\beta 1$-integrins expression in arsenical keratosis and arsenic-treated cultured human keratinocytes. J Cutan Pathol 2006, 33:129-138

16. Lin CS, Chang SC, Wang LS, Chou TY, Hsu WH, Wu YC, Wei YH: The role of mitochondrial DNA alterations in esophageal squamous cell carcinomas. J Thorac Cardiovasc Surg 2010, 139:189-197

17. Sprague RS, Stephenson AH, Ellsworth ML, Keller C, Lonigro AJ: Impaired release of ATP from red blood cells of humans with primary pulmonary hypertension. Exp Biol Med (Maywood) 2001, 226:434-439

18. Liu CY, Lee CF, Wei YH: Activation of PKCdelta and ERK1/2 in the sensitivity to UV-induced apoptosis of human cells harboring $4977 \mathrm{bp}$ deletion of mitochondrial DNA. Biochim Biophys Acta 2009, 1792: 783-790

19. Hwang BJ, Utti C, Steinberg M: Induction of cyclin D1 by submicromolar concentrations of arsenite in human epidermal keratinocytes. Toxicol Appl Pharmacol 2006, 217:161-167

20. Isidoro A, Martinez M, Fernandez PL, Ortega AD, Santamaria G, Chamorro M, Reed JC, Cuezva JM: Alteration of the bioenergetic phenotype of mitochondria is a hallmark of breast, gastric, lung and oesophageal cancer, Biochem J 2004, 378:17-20

21. Kim MM, Clinger JD, Masayesva BG, Ha PK, Zahurak ML, Westra WH, Califano JA: Mitochondrial DNA quantity increases with histopathologic grade in premalignant and malignant head and neck lesions. Clin Cancer Res 2004, 10:8512-8515

22. Cuezva JM, Ostronoff LK, Ricart J, Lopez de Heredia M, Di Liegro CM, Izquierdo JM: Mitochondrial biogenesis in the liver during development and oncogenesis. J Bioenerg Biomembr 1997, 29:365-377 
23. Matsui M, Nishigori C, Toyokuni S, Takada J, Akaboshi M, Ishikawa M, Imamura S, Miyachi Y: The role of oxidative DNA damage in human arsenic carcinogenesis: detection of 8-hydroxy-2'-deoxyguanosine in arsenic-related Bowen's disease. J Invest Dermatol 1999, 113:26-31

24. Vujcic M, Shroff M, Singh KK: Genetic determinants of mitochondria response to arsenic in yeast Saccharomyces cerevisiae. Cancer Res 2007, 67:9740-9749

25. Woo DK, Phang TL, Trawick JD, Poyton RO: Multiple pathways of mitochondrial-nuclear communication in yeast: intergenomic signaling involves ABF1 and affects a different set of genes than retrograde regulation. Biochim Biophys Acta 2009, 1789:135-145

26. Scholz C, Wieder T, Starck L, Essmann F, Schulze-Osthoff K, Dorken $\mathrm{B}$, Daniel PT: Arsenic trioxide triggers a regulated form of caspaseindependent necrotic cell death via the mitochondrial death pathway. Oncogene 2005, 24:1904-1913

27. Banerjee N, Banerjee M, Ganguly S, Bandyopadhyay S, Das JK, Bandyopadhay A, Chatterjee M, Giri AK: Arsenic-induced mitochondrial instability leading to programmed cell death in the exposed individuals. Toxicology 2008, 246:101-111

28. Lau AT, Li M, Xie R, He QY, Chiu JF: Opposed arsenite-induced signaling pathways promote cell proliferation or apoptosis in cultured lung cells. Carcinogenesis 2004, 25:21-28

29. Liao WT, Chang KL, Yu CL, Chen GS, Chang LW, Yu HS: Arsenic induces human keratinocyte apoptosis by the FAS/FAS ligand pathway, which correlates with alterations in nuclear factor $-\kappa$ B and activator protein-1 activity. J Invest Dermatol 2004, 122:125-129

30. Nisoli E, Clementi E, Moncada S, Carruba MO: Mitochondrial biogenesis as a cellular signaling framework. Biochem Pharmacol 2004, 67:1-15

31. Bonawitz ND, Clayton DA, Shadel GS: Initiation and beyond: multiple functions of the human mitochondrial transcription machinery. Mol Cell 2006, 24:813-825
32. Chen H, Liu J, Zhao CQ, Diwan BA, Merrick BA, Waalkes MP: Association of c-myc overexpression and hyperproliferation with arseniteinduced malignant transformation. Toxicol Appl Pharmacol 2001, 175:260-268

33. Zhang D, Li J, Gao J, Huang C: C-Jun/AP-1 pathway-mediated cyclin D1 expression participates in low dose arsenite-induced transformation in mouse epidermal JB6 Cl41 cells. Toxicol Appl Pharmacol 2009, 235:18-24

34. Suliman HB, Carraway MS, Welty-Wolf KE, Whorton AR, Piantadosi CA: Lipopolysaccharide stimulates mitochondrial biogenesis via activation of nuclear respiratory factor-1. J Biol Chem 2003, 278:41510-41518

35. Warburg O: On the origin of cancer cells. Science 1956, 123:309-314

36. Vander Heiden MG, Cantley LC, Thompson CB: Understanding the Warburg effect: the metabolic requirements of cell proliferation. Science 2009, 324:1029-1033

37. Moreno-Sanchez R, Rodriguez-Enriquez S, Marin-Hernandez A Saavedra E: Energy metabolism in tumor cells. FEBS J 2007, 274: 1393-1418

38. Weinberg F, Hamanaka R, Wheaton WW, Weinberg S, Joseph J, Lopez M, Kalyanaraman B, Mutlu GM, Budinger GR, Chandel NS: Mitochondrial metabolism and ROS generation are essential for Kras-mediated tumorigenicity. Proc Natl Acad Sci U S A 2010, 107:8788-8793

39. Chen Y, Cairns R, Papandreou I, Koong A, Denko NC: Oxygen consumption can regulate the growth of tumors, a new perspective on the Warburg effect. PLoS One 2009, 4:e7033

40. Dong X, Ghoshal K, Majumder S, Yadav SP, Jacob ST: Mitochondrial transcription factor $A$ and its downstream targets are up-regulated in a rat hepatoma. J Biol Chem 2002, 277:43309-43318

41. Posey T, Weng T, Chen Z, Chintagari NR, Wang P, Jin N, Stricker H, Liu $\mathrm{L}$ : Arsenic-induced changes in the gene expression of lung epithelial $\mathrm{L} 2$ cells: implications in carcinogenesis. BMC Genomics 2008, 9:115 